\title{
The prognostic value of the myeloid-mediated immunosuppression marker Arginase-1 in classic Hodgkin lymphoma
}

\author{
Alessandra Romano ${ }^{1}$, Nunziatina Laura Parrinello ${ }^{1}$, Calogero Vetro ${ }^{1}$, Daniele \\ Tibullo$^{1}$, Cesarina Giallongo ${ }^{1}$, Piera La Cava ${ }^{1}$, Annalisa Chiarenza ${ }^{1}$, Giovanna \\ Motta $^{1}$, Anastasia L. Caruso ${ }^{1}$, Loredana Villari $^{2}$, Claudio Tripodo $^{3}$, Sebastiano \\ Cosentino ${ }^{4}$, Massimo Ippolito ${ }^{4}$, Ugo Consoli ${ }^{5}$, Andrea Gallamini ${ }^{6}$, Stefano Pileri ${ }^{7}$, \\ Francesco Di Raimondo ${ }^{1}$ \\ ${ }^{1}$ Division of Hematology, AOU "Policlinico - Vittorio Emanuele", University of Catania, Catania, Italy \\ ${ }^{2}$ Division of Pathology, AOU "Policlinico - Vittorio Emanuele", Catania, Italy \\ ${ }^{3}$ Tumor Immunology Unit, Department of Health Science, University of Palermo, Palermo, Italy \\ ${ }^{4}$ Nuclear Medicine Center, Azienda Ospedaliera Cannizzaro, Catania, Italy \\ ${ }^{5}$ Division of Hematology, ARNAS Garibaldi, Catania, Italy \\ ${ }^{6}$ Research, Innovation and Statistics Department. A. Lacassagne Cancer Centre, Nice, France \\ 7Unità di Diagnosi Emolinfopatologica, IEO, Milano, Italy \\ Correspondence to: Alessandra Romano, email: sandrina.romano@gmail.com \\ Francesco Di Raimondo, email: diraimon@unict.it
}

Keywords: Arginase-1, Hodgkin lymphoma, PET-2

Received: June 30, $2016 \quad$ Accepted: September 05, 2016

Published: September 14, 2016

\section{ABSTRACT}

Purpose: Neutrophilia is hallmark of classic Hodgkin Lymphoma (cHL), but its precise characterization remains elusive. We aimed at investigating the immunosuppressive role of high-density neutrophils in $\mathrm{HL}$.

Experimental design: First, $\mathrm{N}-\mathrm{HL}$ function was evaluated in vitro, showing increased arginase (Arg-1) expression and activity compared to healthy subjects. Second, we measured serum level of Arg-1 (s-Arg-1) by ELISA in two independent, training $(N=40)$ and validation $(N=78)$ sets.

Results: s-Arg-1 was higher in patients with advanced stage $(p=0.045)$, B-symptoms $(p=0.0048)$ and a positive FDG-PET scan after two cycles of chemotherapy (PET-2, $p=0.012$ ). Baseline levels of $\mathrm{s}-\mathrm{Arg}-1>200 \mathrm{ng} / \mathrm{mL}$ resulted in $92 \%$ sensitivity and $56 \%$ specificity to predict a positive PET-2.

Patients showing s-Arg-1 levels $>200 \mathrm{ng} / \mathrm{mL}$ had a shorter progression free survival (PFS). In multivariate analysis, PET-2 and s-Arg-1 at diagnosis were the only statistically significant prognostic variables related to PFS (respectively $p=0.0004$ and $p=0.012$ ).

Moving from PET-2 status and s-Arg-1 level we constructed a prognostic score to predict long-term treatment outcome: low S-Arg-1 and negative PET-2 scan (score $0, N=63$ ), with a 3-Y PFS of $89.5 \%$; either positive PET-2 or high s-Arg-1 (score 1, $N=46$ ) with $3-Y$ PFS of $67.6 \%$, and both positive markers (score $2, N=9$ ) with a 3-Y PFS of $37 \%(p=0.0004)$.

Conclusions: We conclude that $\mathrm{N}-\mathrm{HL}$ are immunosuppressive through increased Arg-1 expression, a novel potential biomarker for HL prognosis. 


\section{INTRODUCTION}

Hodgkin Lymphoma (HL) is a neoplastic disorder characterized by a peculiar tumour architecture with few, scattered neoplastic cells surrounded by accessory nonneoplastic reactive cells $[1,2]$. These accessory cells are responsible for the persistent ${ }^{18} \mathrm{~F}$-Fuoro-2-Deoxy-Glucose (FDG) uptake in positron emission tomography (PET) scan performed early after first two cycles of chemotherapy (PET-2) [3-6]. Currently, a positive PET-2 is the main predictor of standard treatment outcome in HL and, accordingly, clinical trials incorporating PET-2 in a riskadapted strategy have shown promising results $[7,8]$. Other clinically relevant prognostic factors in advanced-stage HL include the international prognostic score (IPS) [9], recently validated in a series of advanced-stage patients treated with ABVD (doxorubicin, bleomycin, vinblastine, dacarbazine) regimen [10] and the amount of tumour-associated macrophages (TAM) in the diagnostic biopsy [11].

Several studies have documented the prognostic role of a subset of myeloid cells, defined as "myeloidderived suppressor cells" (MDSC) in several solid and haematological cancers. MDSC phenotype in humans is still controversial [12-16]. Our previous work found that MDSC are increased in HL and have a prognostic significance [17].

MDSC are a heterogeneous set of myeloid cells at different stage of maturation that eventually evolve to the stage of neutrophils with a phenotype largely overlapping that of the granulocytic series [18, 19]. MDSC exert an enforced immune suppressive function against T-lymphocytes, arising from high expression of arginase (Arg-1) [20-23]. In mature neutrophils, Arg1 is constitutively produced and stocked in cytoplasmic azurrophil granules [24-26] to be readily released during inflammation, to deplete the milieu of arginine [22].

Arg-1 metabolizes L-arginine to L-ornithine and urea in cytosol [22]. In T-cells, Arg-1 induces depletion of arginine from the microenvironment, an essential amino acid for the effective function of T-cell receptor (TCR) zeta chain assembly and downstream signalling [23, 27] as a consequence, L-arginine depletion profoundly suppresses $\mathrm{T}$ cell immune responses and this has emerged as a fundamental mechanism of inflammation-associated immunosuppression [19, 28-31].

Since both leucocytosis and lymphopenia have been incorporated in IPS because prognostically relevant [9], we explored the functional activity of neutrophils in HL (HL-N), their relation with disease burden and the prognostic value of their product, Arg-1.

\section{RESULTS}

\section{Neutrophils are dysfunctional and immunesuppressive in $\mathrm{HL}$}

Phagocytic activity was reduced in HL-N at diagnosis compared to healthy subjects (Figure 1A).
In order to understand if this finding was due to a persistence or lack of activation we investigated the neutrophil activation marker CD11b, because it promotes the phagocytosis of iC3b-coated particles and its expression increases rapidly following phagocyte activation. The MFI of the activation marker CD11b on HL-N was higher than CTRL-N $(N=40,25.3 \pm 1.3$ versus $15.6 \pm 0.8 \mathrm{au}, p<0.0001$, Figure 1B) and reduced up to normal values after two courses of chemotherapy (as shown in 15 patients, $26.5 \pm 1.1$ versus $16.5 \pm 1.0, p=$ 0.0002 , Figure 1C).

In order to detect if a soluble factor, HL related, could explain these changes in N, we incubated for 24 hours 4 CTRL-N with serum obtained from HL or healthy donors and we observed that HL serum induced an increase of CD11b MFI ( $p=0.02$, Figure 1D).

Lymphocytes isolated from 5 healthy subjects (hLy) were co-cultured with neutrophils isolated from fresh peripheral blood of $8 \mathrm{HL}$ patients (HL-N) and 5 healthy subjects (CTRL-N) in order to evaluate markers of activation after stimulation with PHA-P up to 72 hours in six independent experiments. In presence of HL-N, proliferation of T-cells was inhibited, in a dose-dependent manner (Supplementary Figure 2A). Similarly, despite PHA-P stimulation for 48 hours, CD69, CD71, HLA$\mathrm{DR}$ and $\mathrm{CD} 3 \zeta$ expression in h-Ly remained low after co-culture with HL-N, but not with CRTL-N, in a dosedependent manner by increasing the ratio from 1:2 to $1: 4$ to 1:8 (Supplementary Figure 2B-2E). Treatment with 200 $\mu \mathrm{M}$ nor-NOHA (an Arg-1 inhibitor) for 48 hours reverted significantly this immunosuppressive effect, both at level of activation marker expression (Figure 2A-2C) and T-cell proliferation (Figure 2D).

\section{Arg-1 is increased in HL patients}

Basic characteristics and treatments of both sets of patients are summarized in Table 1. Median age was 33 years (range 18-74) in the training set and 37 years (range 16-68) in the validation set. In both sets, most patients had advanced disease (Ann-Arbor stage $\geq$ IIB) and nodular sclerosis histotype. All except 5 had a history of infectious mononucleosis with positive antibody titre to the EBV viral capsid antigen.

By RT-PCR, we measured ARG-1 in white blood cells (PBWC) and we found a marked increase of Arg- 1 expression of HL samples, almost entirely sustained by neutrophils (Figure 3A). Western blot of proteins obtained from HL-N confirmed this observation (Figure 3B). Neutrophils from HL patients showed also increased arginase activity in comparison to healthy subjects (Figure 3C).

To link the neutrophil dysfunction found in the peripheral blood of HL patients with the peculiar immunological milieu of the disease, we investigated the expression of Arg-1 in situ. Within the HL microenvironment, Arg-1-expressing cells with granulocytic and monocytic morphology were found intermingling with malignant cells 
Table 1: Patients' characteristics

\begin{tabular}{|c|c|c|c|}
\hline & $\begin{array}{c}\text { Training set } \\
N=40(100 \%)\end{array}$ & $\begin{array}{c}\text { Validation set } \\
N=78(100 \%)\end{array}$ & $p$-value \\
\hline Median age (range) & $33(18-74)$ & $37(16-68)$ & \\
\hline $\operatorname{Sex}(M / F)$ & $24 / 16$ & $48 / 30$ & 0.98 \\
\hline Bulky disease (Yes/No) & $11 / 29$ & $11 / 67$ & 0.08 \\
\hline B-symptoms present (Yes/No) & $25 / 15$ & $46 / 32$ & 0.84 \\
\hline Lymphocyte count/10^3uL median (range) & $1.33 \pm 0.15$ & $1.38 \pm 0.31$ & 0.51 \\
\hline Neutrophil count/10^3uL median (range) & $8.58 \pm 1.81$ & $8.89 \pm 1.63$ & 0.35 \\
\hline \multicolumn{4}{|l|}{ Ann Arbor stage } \\
\hline Early disease & $9(22.5)$ & $28(35.9)$ & 0.14 \\
\hline Advanced disease & $31(77.5)$ & $50(64.1)$ & \\
\hline \multicolumn{4}{|l|}{ Hystotype } \\
\hline Nodular sclerosis (\%) & $30(75)$ & $60(77.5)$ & \\
\hline Mixed cellularity (\%) & $3(7.5)$ & $9(12.5)$ & \\
\hline Lymphocyte-rich (\%) & $7(17.5)$ & $6(7.5)$ & \\
\hline Lymphocyte-depleted (\%) & $0(0)$ & $3(2.5)$ & \\
\hline \multicolumn{4}{|l|}{ IPS (only for advanced stage) } \\
\hline$<2$ & 5 & 19 & 0.04 \\
\hline $2-7$ & 26 & 29 & \\
\hline LDH median (range) & $386 \pm 56$ & $397 \pm 47$ & 0.26 \\
\hline ESR median (range) & $45 \pm 23$ & $52 \pm 31$ & 0.21 \\
\hline $\begin{array}{l}\text { Treatment } \\
\text { ABVD } 2 \text { cycles } \pm \text { i.f. radiotherapy } \\
\text { ABVD } 4 \text { cycles } \pm \text { i.f. radiotherapy } \\
\text { ABVD } 6 \text { cycles } \\
\text { ABVD } 2 \text { cycles }+ \text { BEACOPP } 8 \text { cycles }\end{array}$ & $\begin{array}{c}3(7.5) \\
3(7.5) \\
29(72.5) \\
5(12.5)\end{array}$ & $\begin{array}{c}2(2.5) \\
26(33.5) \\
41(52.5) \\
9(11.5)\end{array}$ & \\
\hline
\end{tabular}

Clinical features of patients at baseline and their first-line treatment.

Abbreviations: LDH: lactico-dehydrogenase, ESR: Erythrocyte Sedimentation Rate, C-RP: C-Reactive Protein; i.f. involved field.

(Figure 3D-3E). Arg-1+ cells were significantly enriched in HL tissue samples as compared with control reactive lymph node samples, in which only few scattered Arg-1expressing elements were found within T-cell rich areas (Figure 3F). The myeloid lineage of Arg-1+ cells infiltrating HL were confirmed by double immunofluorescence analysis with CD68, clone KP1, which highlights myelomonocytic elements (Figure 3G, upper panels). Moreover, the suppressor phenotype of Arg-1+ myeloid elements within HL microenvironment was also supported by double immunofluorescence for indoleamine 2,3-dioxygenase IDO (an enzyme acting as immune modulator through suppression of T-cell immunity, highly expressed in HL microenvironment and associated to poor outcome [32] which revealed that Arg- $1+$ cells also expressed IDO (Figure 3G, lower panels). Intensity of Arg-1 was independent from CD68 staining and clinical variables in the training set (data not shown).
When we measured circulating Arg-1 in the serum of an enlarged cohort of patients (training+validation sets), we found it was increased in HL patients at diagnosis compared to healthy volunteers, mean \pm standard deviation (SD) $174.6 \pm 10.3$ versus $51.5 \pm 4.9 \mathrm{ng} / \mathrm{mL}(N=118$, $p<0.0001$, Figure 4A). During and after standard first-line ABVD therapy Arg- 1 was reduced: $78.6 \pm 5.8 \mathrm{ng} / \mathrm{mL}$ after two cycles and $46.7 \pm 3.4 \mathrm{ng} / \mathrm{mL}$ at the end of the planned cycles (Figure 4B, ANOVA $p<0.0001$ ).

We then correlated the measurement of Arg-1 in the serum at diagnosis with clinical findings. We found that patients with positive PET-2 showed higher Arg-1 at diagnosis compared to those who carried a negative PET2 $(147.2 \pm 9.1$ versus $309.1 \pm 25.8 \mathrm{ng} / \mathrm{mL}$, $p<0.0001$, Figure 4C). Similarly, patients who achieved complete remission exhibited lower levels of Arg-1 compared to relapsed/refractory ones at diagnosis 
$(149.2 \pm 9.4$ versus $269.2 \pm 26.1 \mathrm{ng} / \mathrm{mL}, p<0.0001$, Figure 4D).

Arg-1 was increased in patients with advanced disease, B-symptoms, and elevated ESR in early-stage patients as shown in Supplementary Figure 3 for both training and validation sets.

\section{High Arg-1 amount is associated to shorter PFS}

In the training set, 9/40 (22.5\%) patients had s-Arg-1 at diagnosis higher than $200 \mathrm{ng} / \mathrm{ml}$, and six of them had positive PET-2 and were addressed to an early salvage therapy accordingly to BEACOPP scheme, 3/6 achieving complete remission. A level of $200 \mathrm{ng} / \mathrm{mL}$ Arg-1 resulted in $87 \%$ (95\% C.I. 71-96) sensitivity and $62 \%$ (95\% C.I. 25-92) specificity in predicting achievement of complete response in the training set (area under curve, AUC, 0.81, $p=0.0078$ ). Thus, a cut-off level of $200 \mathrm{ng} /$ $\mathrm{mL}$ for s-Arg-1 was chosen to predict response status at 24 months (Table 2).

In the validation set, baseline levels of s-Arg-1 > $200 \mathrm{ng} / \mathrm{mL}$ resulted in $73 \%$ (C.I. 95\% 60-84) sensitivity
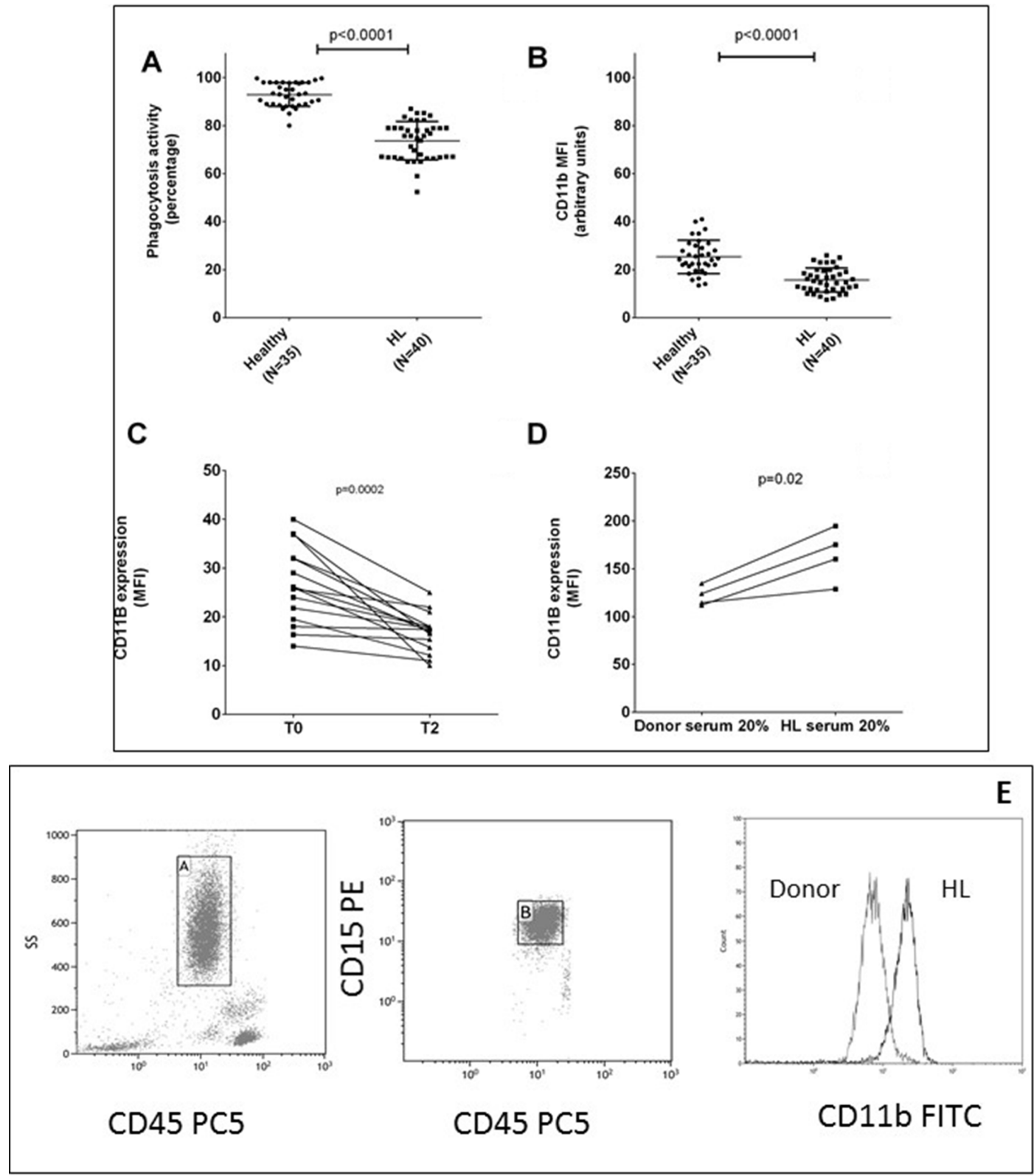

Figure 1: Neutrophils are dysfunctional in HL. Mean values \pm DS of phagocytosis test in neutrophils are shown from HL patients and healthy subjects in duplicate (panel A). Mean fluorescence intensity (MFI) of CD11b in neutrophils was evaluated at diagnosis (panel B) and after 2 courses of ABVD therapy (panel C). Neutrophils isolated from 4 healthy donors in two independent experiments were incubated for 24 hours with RPMI media plus $20 \%$ of serum obtained from healthy donor or HL patients in order to evaluate any change in CD $11 \mathrm{~b}$ MFI (panel D). Gating strategy for CD11b expression on neutrophils is shown in (panel E). 
and $83 \%$ (C.I. 95\% 59-96) specificity in predicting response status at 24 months follow-up. Since the PET2-oriented therapeutic approach, we evaluated also the ability of s-Arg-1 to predict PET-2 status, as reported in Table 2.

In the validation set, patients with high s-Arg-1 had shorter PFS at 24 months than patients with low Arg-1 (56.2\% vs 93.4\%, $p<0.0001$, Supplementary Figure 4A), similarly to what described based on PET-2 status $(28.7 \%$ vs $88.9 \%, p<0.0001$, Supplementary Figure 4B).

Thus, in the whole cohort of 118 patients, PFS at 36 months was $89.8 \%$ for patients with low s-Arg-1 versus $55.5 \%$ in patients with high s-Arg-1 (Figure 5A). Based on PET-2 scan, PFS at 36 months was $83.3 \%$ in patients with negative scan and $53.2 \%$ in patients with positive scan, despite an early salvage treatment in patients with positive PET-2 scan (Figure 5B). In the group of PET-2 negative patients $(N=97)$, PFS at 36 months was $95.6 \%$ for patients with low s-Arg-1 $(n=69)$ versus $68.7 \%$ in patients with high s-Arg-1 $(N=18, p=0.001$, Figure $5 \mathrm{C})$.

In multivariate analysis, PET-2 and s-Arg-1 at diagnosis were the only significant prognostic variables
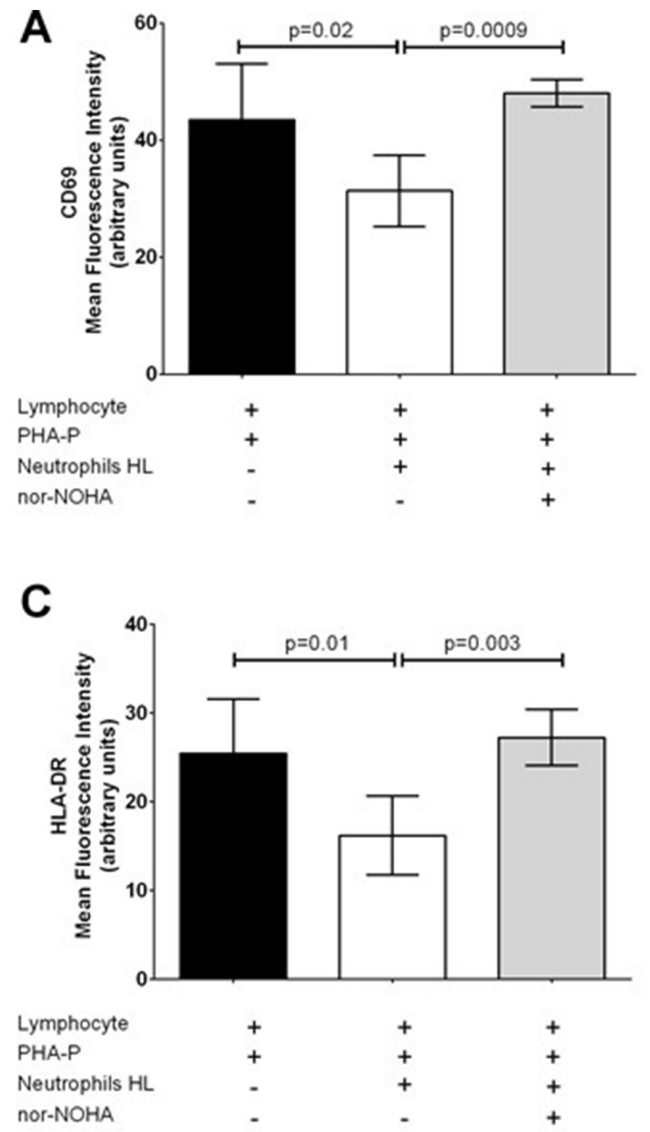

(respectively $p=0.0004$ and $p=0.012$, Table 3 ), despite the limited size of the sample and the adopted therapeutic strategy including early shift to BEACOPP treatment in case of PET-2 positivity.

With these two prognostic variables, we were able to define three distinct groups of patients based on PET-2 status after two cycles of chemotherapy and s-Arg-1 level at diagnosis. Figure 5D shows the PFS curves in patients with low s-Arg-1 and negative PET-2 scan (score $0, N=$ $63,53 \%$ ) or at least one unfavourable prognostic factors (score $1, N=46,40 \%$ ) or high s-Arg-1 and positive PET-2 (score $2, N=9,7 \%$ ).

Patients with score 0 had $89.5 \%$ PFS at 36 months versus $67.6 \%$ for patients with score 1 versus $37 \%$ for patients with score $2(p=0.0004)$.

\section{DISCUSSION}

We previously showed that MDSC are increased in HL and have a prognostic role [17]. We therefore focused on neutrophils since neutrophilia is a common clinical finding in HL, and together with a low lymphocytes count

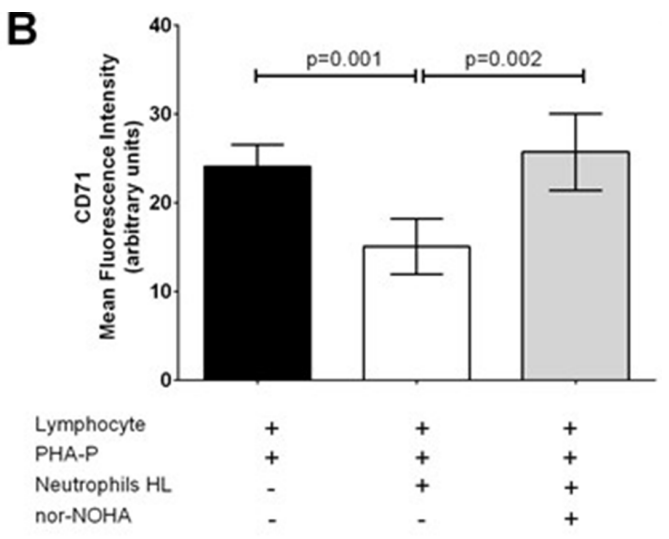

D

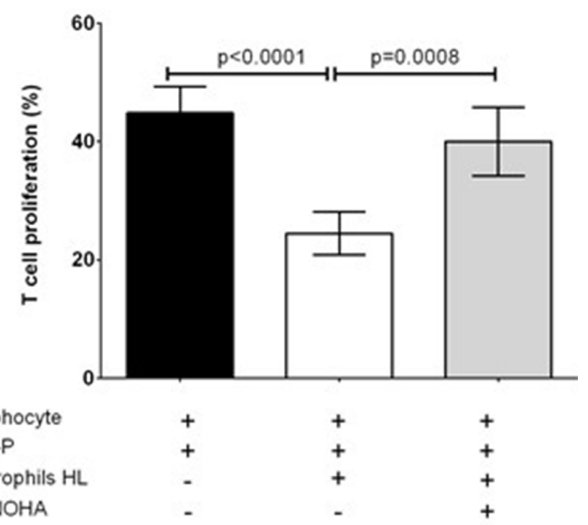

Figure 2: Immunosuppressive effect of HL neutrophils on T-cells can be reverted by nor-NOHA. Results at 48 hours are reported separately for activation marker expression of CD69 (A), CD71 (B), HLA-DR (C) and proliferation (D) in h-Ly co-cultured with HL-N in absence (white bars) or in presence of $200 \mu \mathrm{M}$ nor-NOHA (grey bars). Results represent MFI mean \pm SD of duplicates from four donors and four patients, and are representative of three independent experiments. 
Table 2: Arg-1 at diagnosis can predict early (PET-2 status) and long term (relapse/refractory disease at 24 months follow-up) outcome of HL patients

\begin{tabular}{|c|c|c|c|c|c|c|}
\hline & \multicolumn{3}{|c|}{ Training set $(n=40)$} & \multicolumn{3}{|c|}{ Validation set $(n=78)$} \\
\hline & $\begin{array}{l}\text { Complete } \\
\text { remission @ } \\
24 \text { months } \\
\text { (N 32) }\end{array}$ & $\begin{array}{c}\text { Relapse/ } \\
\text { Refractory disease } \\
\text { (N 8) }\end{array}$ & $\begin{array}{c}\text { R/R status @ } \\
24 \text { months }\end{array}$ & $\begin{array}{c}\text { Complete remission } \\
\text { @ } \\
24 \text { months } \\
\text { (N 60) }\end{array}$ & $\begin{array}{c}\text { Relapse/ } \\
\text { Refractory disease } \\
\text { (N 18) }\end{array}$ & $\begin{array}{c}\text { R/R status@ } \\
24 \text { months }\end{array}$ \\
\hline $\begin{array}{l}\text { Arg-1 } \\
<200 \mathrm{ng} / \mathrm{mL}\end{array}$ & 28 & 3 & $\begin{array}{c}p=0.0078 \\
\text { Sensitivity } \\
87 \%(71-96)\end{array}$ & 44 & 3 & $\begin{array}{c}p<0.0001 \\
\text { Sensitivity } \\
73 \%(60-84)\end{array}$ \\
\hline \multirow{4}{*}{$\begin{array}{l}\text { Arg-1 } \\
\geq 200 \mathrm{ng} / \mathrm{mL}\end{array}$} & 4 & 5 & $\begin{array}{c}\text { Specificity } \\
62 \%(25-92)\end{array}$ & 16 & 15 & $\begin{array}{c}\text { Specificity } \\
83 \%(59-96)\end{array}$ \\
\hline & & & $\begin{array}{c}\text { PPV } \\
90 \%(74-98)\end{array}$ & & & $\begin{array}{c}\text { PPV } \\
93 \%(82-98)\end{array}$ \\
\hline & & & $\begin{array}{c}\text { NPV } \\
56 \%(21-86)\end{array}$ & & & $\begin{array}{c}\text { NPV } \\
48 \%(30-66)\end{array}$ \\
\hline & $\begin{array}{l}\text { Complete } \\
\text { remission @ } \\
24 \text { months } \\
\text { (N 32) }\end{array}$ & $\begin{array}{c}\text { Relapse/ } \\
\text { Refractory disease } \\
\text { (N 8) }\end{array}$ & $\begin{array}{c}\text { R/R status @ } \\
24 \text { months }\end{array}$ & $\begin{array}{c}\text { Complete remission } \\
@ \\
24 \text { months } \\
\text { (N 60) }\end{array}$ & $\begin{array}{c}\text { Relapse/ } \\
\text { Refractory disease } \\
\text { (N 18) }\end{array}$ & $\begin{array}{c}\text { R/R status @ } \\
24 \text { months }\end{array}$ \\
\hline Negative scan & 30 & 4 & $\begin{array}{c}p=0.009 \\
\text { Sensitivity } \\
93 \%(79-99)\end{array}$ & 55 & 8 & $\begin{array}{c}p<0.0001 \\
\\
\text { Sensitivity } \\
92 \%(82-97)\end{array}$ \\
\hline \multirow{4}{*}{$\begin{array}{l}\text { Positive } \\
\text { scan }\end{array}$} & 2 & 4 & $\begin{array}{c}\text { Specificity } \\
50 \%(16-84)\end{array}$ & 5 & 10 & $\begin{array}{c}\text { Specificity } \\
56 \%(31-78)\end{array}$ \\
\hline & & & $\begin{array}{c}\text { PPV } \\
88 \%(73-96)\end{array}$ & & & $\begin{array}{c}\text { PPV } \\
87 \%(77-94)\end{array}$ \\
\hline & & & $\begin{array}{c}\text { NPV } \\
67 \%(23-95)\end{array}$ & & & $\begin{array}{c}\text { NPV } \\
67 \%(38-88)\end{array}$ \\
\hline & $\begin{array}{l}\text { Negative scan } \\
\text { (N 34) }\end{array}$ & $\begin{array}{c}\text { Positive scan } \\
\text { (N 6) }\end{array}$ & PET-2 status & $\begin{array}{l}\text { Negative scan } \\
\text { (N 63) }\end{array}$ & $\begin{array}{l}\text { Positive scan } \\
\text { (N 15) }\end{array}$ & PET-2 status \\
\hline $\begin{array}{l}\text { Arg-1 } \\
<200 \mathrm{ng} / \mathrm{mL}\end{array}$ & 30 & 1 & $\begin{array}{c}p=0.01 \\
\text { Sensitivity } \\
88 \%(73-96)\end{array}$ & 42 & 5 & $\begin{array}{c}p=0.03 \\
\text { Sensitivity } \\
67 \%(54-78)\end{array}$ \\
\hline & 4 & 5 & $\begin{array}{c}\text { Specificity } \\
83 \%(36-99)\end{array}$ & 21 & 10 & $\begin{array}{c}\text { Specificity } \\
67 \%(39-88)\end{array}$ \\
\hline$\geq 200 \mathrm{ng} / \mathrm{mL}$ & & & $\begin{array}{c}\text { PPV } \\
96 \%(85-99) \\
\text { NPV } \\
56 \%(21-86)\end{array}$ & & & $\begin{array}{c}\text { PPV } \\
89 \%(76-96) \\
\text { NPV } \\
33 \%(16-51)\end{array}$ \\
\hline
\end{tabular}

We reported sensitivity, specificity, positive predictive value (PPV) and negative predictive value (NPV) in the training and validation set for Arg-1 as biomarker predictive of PFS at 24 months. 95\% confidence interval are reported in round brackets. 


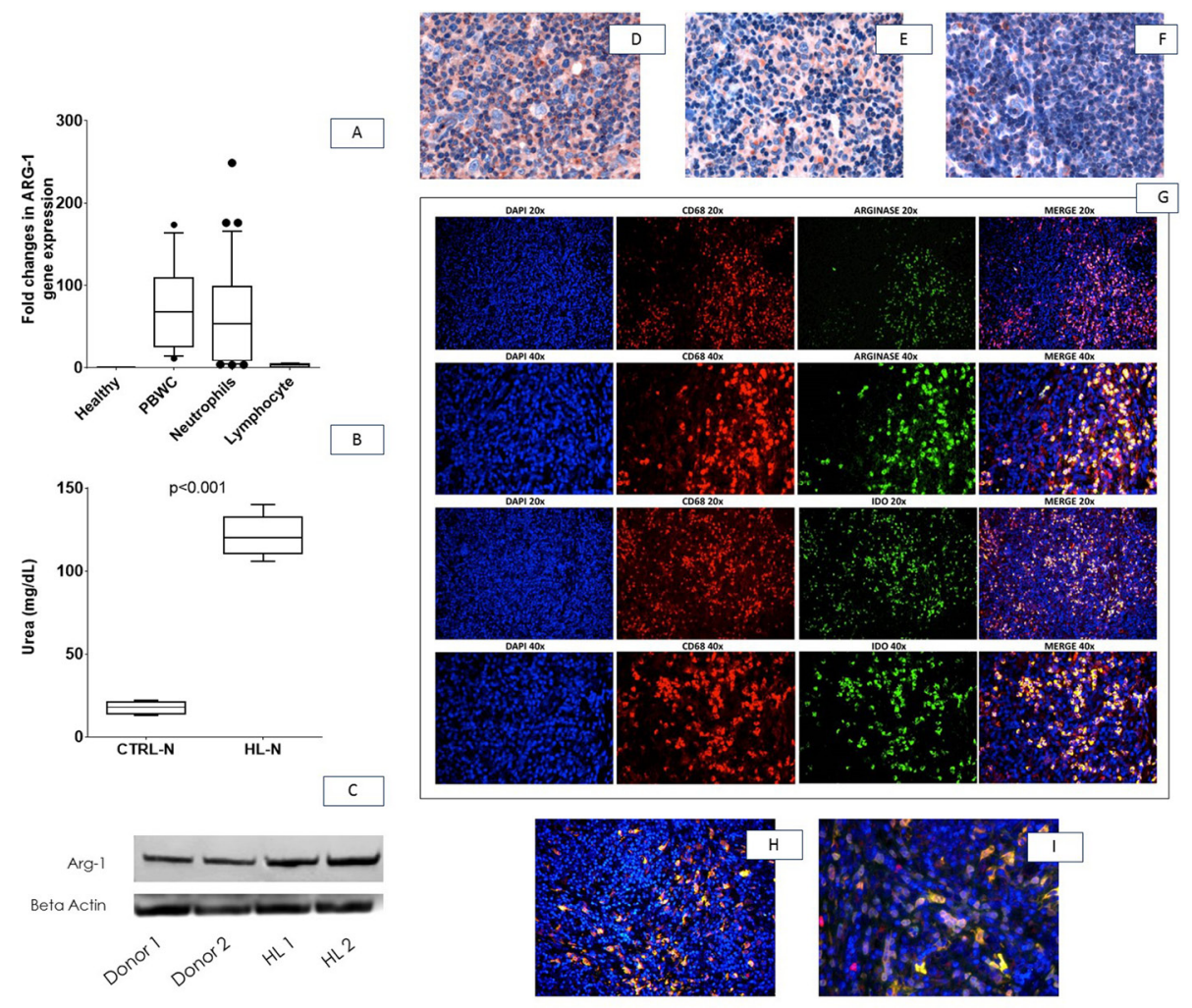

Figure 3: Arg-1 expression in neutrophils and lymph-node microenvironment. Neutrophils isolated from control and HL patients were analysed for Arg-1 expression (A), activity by measuring urea (B) and protein expression by Western Blot (C). All assays were performed in triplicate. Representative microphotographs relative to Arg-1 in situ immunohistochemical detection in a case of mixed cellularity cHL (D), nodular sclerosis cHL (E), and in a lymph-node with reactive follicular hyperplasia (F). Double-marker immunofluorescence revealing that Arg- $1^{+}$cells within cHL environment were positive for CD68 (clone KP1, G upper panels) and IDO (Figure 3H-3I) (20 and 40× magnification).Abbreviations: CTRL-N: pool of neutrophils from healthy subjects; HL-N: pool of neutrophils from Hodgkin`s Lymphoma at diagnosis; Arg-1: Arginase 1
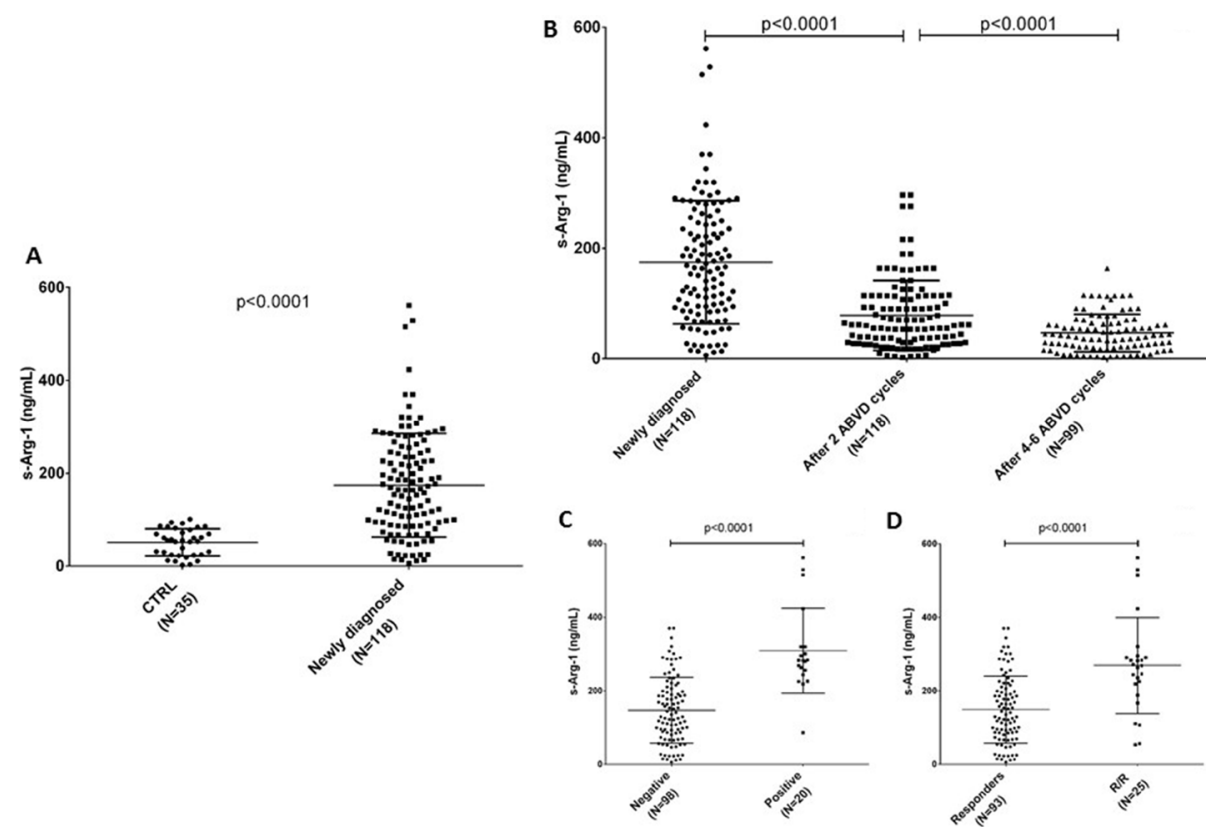

Figure 4: s-Arg-1 is increased in HL. Concentration of arginase in serum (s-Arg-1) is reported for healthy volunteers and HL patients at diagnosis (panel A). Reduction in s-Arg-1 occurred by first two months of ABVD treatment, deeper at the end of planned treatment (B), except for PET-2 positive (panel C) or non-responder patients (panel D). 
Table 3: Cox proportional hazard regression analysis

\begin{tabular}{cccc}
\hline Variable & HR & $\mathbf{9 5 \% C I ~ f o r ~ H R ~}$ & $\boldsymbol{p}$-value \\
\hline PET-2 & 4.6 & $2.1-10.8$ & 0.0004 \\
WBC $>$ 15,000 cells/uL & 1.6 & $0.28-13.3$ & 0.58 \\
s-Arg-1 & 3.3 & $1.3-8.4$ & 0.01 \\
B-symptoms & 1.8 & $0.32-12.3$ & 0.62 \\
\hline
\end{tabular}

Abbreviations: HR hazard ratio, WBC: white blood cells.

is associated with a poor prognosis [9]. The imbalance between myeloid and lymphoid arm has been proposed as an additional biomarker in HL, including the ratio between the absolute counts of monocytes and lymphocytes [33]. However, the prognostic value of all the above markers was superseded by PET-2 [4].

In this work we investigated the function of neutrophils isolated from patients affected by HL sorted by physical methods. We found that N-HL are dysfunctional, since they exhibit a reduced phagocytic activity despite presence of activation signalling as shown by high levels of $\mathrm{CD} 11 \mathrm{~b}$ on the surface, as consequence of a

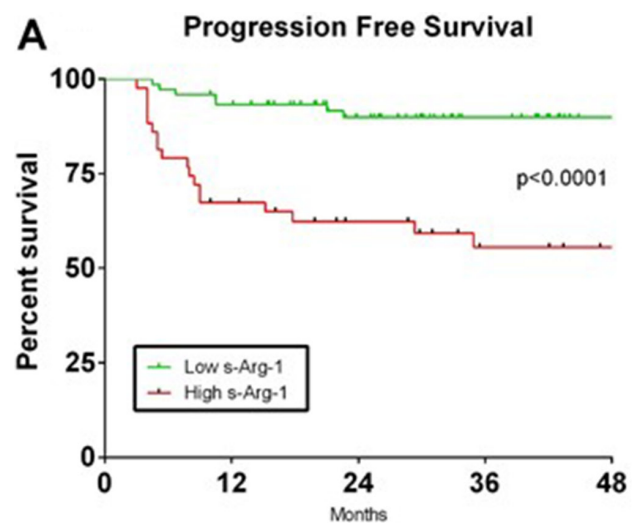

C

Progression Free Survival

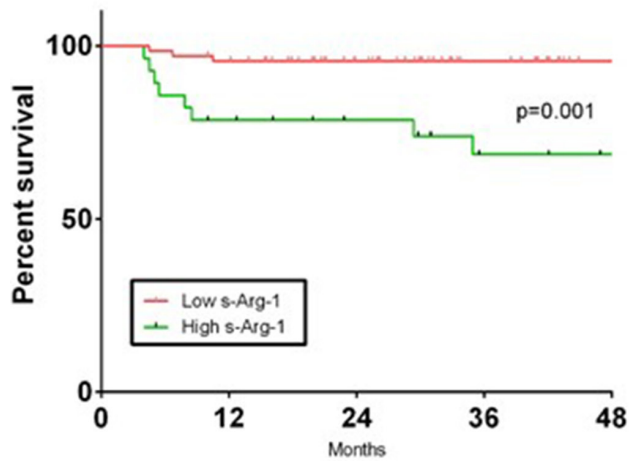

sterile chronic inflammation leaded by soluble factors in HL including TGF-beta and IL-6 [34]. This uncoupled stimulation is likely due to one or more soluble factor(s) deserving specific investigation in further works.

We demonstrated that neutrophils of HL patients are able to reduce $\mathrm{CD} 3 \zeta$ expression and other activation markers on the cell surface of T-lymphocytes stimulated with PHA-P (Figure 2), pointing toward an immunosuppressive activity of $\mathrm{N}-\mathrm{HL}$ on normal lymphocytes. Downregulation of $\mathrm{CD} 3 \zeta$ is a frequent mechanism of immunosuppression occurring in patients with solid cancers $[19,35-37]$. The inflammatory

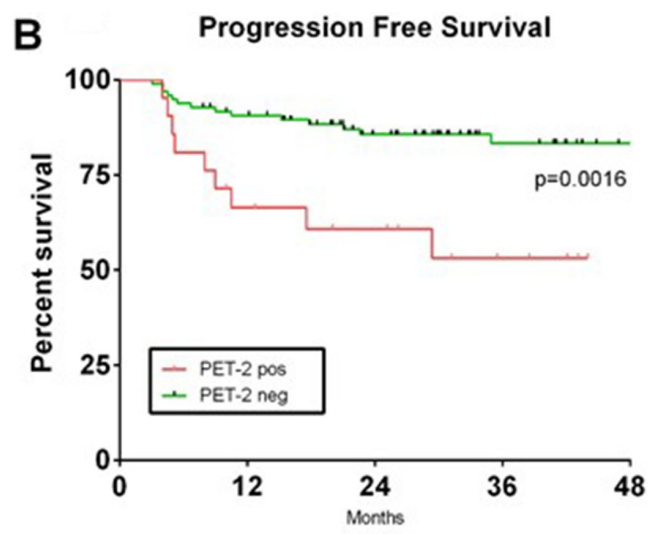

D

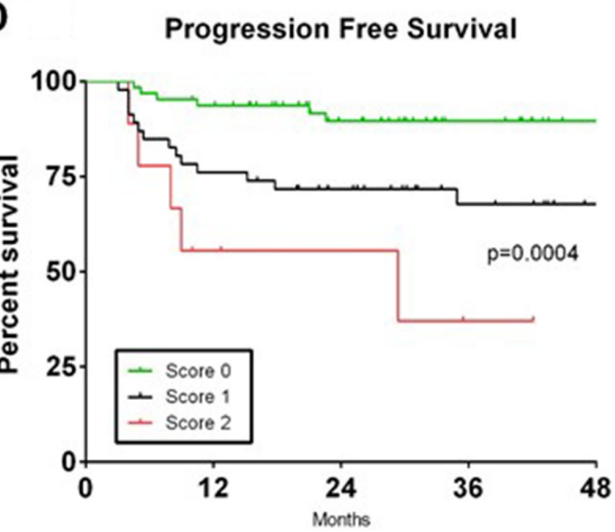

Figure 5: Progression free survival based on combination of PET-2 status and s-Arg-1 level. Kaplan-Meier curves of progression free survival based on s-Arg-1 at diagnosis (panel A) and PET-2 scan (panel B) in the whole cohort of 118 patients are shown. Progression free survival in the cohort of patients carrying negative PET-2 based on s-Arg-1 is shown in (panel C). A score was developed based on PET-2 status after two cycles of chemotherapy and s-Arg-1 level at diagnosis (Panel D). Patients with low s-Arg-1 and negative PET-2 scan had score 0 , patients with high s-Arg-1 or positive PET-2 scan had score 1 and patients with high s-Arg-1 and positive PET-2 scan had score 2. 
environment may contribute to the accumulation of both mature neutrophils and MDSC. PMN from healthy donors activated with N-formil-L-methyonil-L-leucyl-Lphenylalanine co-purify with PBMC and suppress T-cells in a dose-dependent manner [38], similarly to mature neutrophils isolated from patients affected by sepsis [39] or mature neutrophils isolated from volunteers treated with LPS [34]. In absence of reliable markers to distinguish in human between normal mature neutrophils and G-MDSC, we hypothesized that aberrant function of HL-N could be due to a chronic stimulation (as suggested by CD11b expression) to sequentially downregulated T-cell function and inhibited effector responses during the transition to memory cells [40]. Indeed, we hypothesized that this immunosuppressive activity is mediated by Arg-1.

Arg-1 is contained in neutrophils, at the level of cytoplasmic azurophil granules as reported in most cases $[24,26,41]$ but also in gelatinase grains [25]. Arg-1 modifies the metabolism of L-arginine, including the dephosphorylation of cofilin, which is needed for the stability of the immunological synapse [42] and downregulates the CD3 $\zeta$ chain translation in T cells, contributing to inhibit T cell proliferation $[19,22,29-31]$.

In our study on neutrophil functional activity we showed that HL-N are characterised both by increased levels and activity of Arg-1 compared to healthy subjects (Figure 3). This is probably responsible for the increased Arg-1 serum levels that we have found in HL patients. In particular, s-Arg-1 levels proved higher in the serum of HL patients at diagnosis and promptly decreased upon effective treatment.

In both training and validation sets we found that Arg-1 is correlated to clinical features at baseline (stage, B symptoms, and elevated ESR). Most important, an Arg-1 serum level $>200 \mathrm{ng} / \mathrm{mL}$ at diagnosis represents a negative prognostic factor, able to predict response status at 24 months. In addition, we found that Arg-1 in some extend is able to predict PET-2 positivity, which remains, according to several recent reports the most important predictive factor on treatment outcome [3, 43-45]. This assumption has been also confirmed by our data, showing that a positive PET-2 may indeed identify patients candidate to a more aggressive treatment [45].

However, PET-2 information is available only during treatment and biological mechanisms leading to chemo-resistance may be activated as early as after 2 cycles of ABVD treatment. On the contrary, s-Arg-1 is a true prognostic factor, readily available at baseline before treatment onset, giving information that can be extremely useful for clinicians. Alternatively, it could be used as complementary information together with PET-2. Indeed, we found that Arg-1 and PET-2 can be combined in a prognostic score with three different probabilities of outcome.

In the last years, many studies have indicated the prognostic role in HL of serum cytokines, such as soluble
CD30, IL-6, Il-2R or activation-related chemokine (TARC) [46]. However, different from the latter, Arg1 is a specific marker of tumour functional activity as it portrays the T-lymphocyte suppression by HL. Future studies should explore the relationship of Arg-1 with other significant cytokines in HL to define a "cytokine fingerprint" in a single-patient basis with a strong potential prognostic impact.

In HL lymph nodes, high number of Arg- $1^{+}$myeloid cells are significantly associated to shorter progression free survival in early stage patients and are correlated with a worse overall survival. In particular, a fraction of CD68KP1+ elements do also express Arg-1 in immunofluorescence [47]. Whether the prognostic value of MDSC Arg-1+ overlaps with that of TAM CD68KP1+ in HL [11] is still under investigation.

In conclusion, s-Arg-1 levels higher than $200 \mathrm{ng} / \mathrm{mL}$ are associated to a shorter PFS in HL. This observation needs to be prospectively confirmed in a larger series of patients.

\section{MATERIALS AND METHODS}

\section{Patients}

Peripheral blood samples were prospectively collected from 118 consecutive newly diagnosed patients treated at the Division of Haematology, AOU PoliclinicoOVE, University of Catania between August 2012 and June 2014. First 40 cases were defined as training set (since these samples were used for functional evaluations), and further 78 patients considered as validation set. Thirtyfive healthy subjects were evaluated as controls. The study was approved by the local IRB. All participants signed a written informed consent in accord to the Declaration of Helsinki.

The advanced-stage patients included in the present study were enrolled in the prospective multicenter phase II clinical trial HD 0607, as elsewhere reported [8]. Briefly, treatment started with 2 ABVD cycles $[48,49]$ and an interim PET (PET-2) was performed afterwards. On the basis of PET-2 results, patients with a positive scan shifted to a more aggressive treatment with BEACOPP regimen (bleomycin, etoposide, doxorubicin, cyclophosphamide, vincristine, procarbazine, and prednisone), four escalated + four baseline cycles; patients with a negative PET2 continued with standard ABVD treatment [8]. Early stage patients received two or four courses of ABVD chemotherapy plus involved field radiotherapy as clinically indicated.

\section{FDG-PET scan assessment}

Both baseline and interim PET were performed using standard scanning protocol. The scans were acquired at $60 \pm 10^{\prime}$ (early) after the injection of the tracer and a 
semi-quantitative Deauville score was attributed to each image; scans were centrally reviewed by a panel of nuclear medicine experts in the HD 0607 trial, and by two local reviewers in early stage (I-IIA) disease [50, 51]. Only frankly positive and minimally positive scans were reviewed. A minimally positive scan was defined as any scan with any residual FDG uptake outside the physiological areas of the tracer concentration (mediastinal blood pool and liver) [43].

\section{Reagents}

Ficoll-Paque was obtained from Pharmacia LKB Biotechnology. Heat inactivated/gamma-irradiated fetal bovine serum was obtained from Gibco Industries (Carlsbad, Ca). RPMI 1640 media with L-glutamine (1x), Dulbecco's phosphate-buffered saline (D-PBS) were purchased from Celbio, Italy and phytohemagglutinin (PHA-P) was obtained from Sigma-Aldrich (St. Louis, MO, USA).

The following anti-human antibodies were purchased from Beckman Coulter: HLA-DR- PC5 (Clone Immu-357), CD45 PC5 (clone J.33), CD15 PE (clone 80H5), CD3 ECD (clone UCHT1), HLA-DR- PC5 (Clone Immu-357), CD69 PE (clone TP1.55.3), CD71 FITC (clone DYJ1.2.2), CD11b FITC (clone Bear1) while $\mathrm{CD} 3 \zeta / \mathrm{CD} 247 \mathrm{PE}$ (clone 6B10.2) was purchased from eBioscience. Fluorescent-labeled isotype matched control antibodies were also purchased from Beckman Coulter, used as negative controls.

\section{Phagocytosis assay}

Phagocytic activity of myeloid compartment was detected using the Phagotest kit (Opregen Pharma, Heidelberg, Germany).

Briefly, $100 \mu \mathrm{l}$ heparinized whole peripheral blood is incubated with $20 \mu \mathrm{l}$ opsonized FITC-labeled Escherichia coli for $10 \mathrm{~min}$ at $37^{\circ} \mathrm{C}$ in a water bath and in parallel a negative control sample remained on ice. The phagocytosis was stopped by placing the samples on ice. To eliminate the fluorescence of non-phagocytized bacteria, $100 \mu \mathrm{l}$ of quenching solution were added. After a wash with $3 \mathrm{ml}$ of washing solution ( $5 \mathrm{~min}, 250 \times \mathrm{g}$, $4^{\circ} \mathrm{C}$ ), the cells were incubated for $10 \mathrm{~min}$ on ice in $200 \mu \mathrm{l}$ of DNA and analyzed by flow cytometry using a Coulter EPICS-XL-MCL cytometer.

Neutrophils were gated through the scatter parameters (forward, FCS vs side, SSC) and their green fluorescence histogram was analyzed. The phagocytic ability was expressed as percentage of fluorescent cells in the population studied and calculated by subtracting the percentage of the negative control sample $(<1 \%)$ from the positive sample.

\section{Isolation of neutrophils and lymphocytes}

Whole blood $(40 \mathrm{ml})$ was collected from healthy volunteers and HL patients in EDTA vacutainer tubes and diluted 1:1 with Dulbecco's phosphate buffered saline (PBS) (Celbio). Peripheral blood mononuclear cells (PBMC) were then isolated by density gradient centrifugation with Ficoll-Paque (Pharmacia LKB Biotechnology).

The resulting layer from the gradient was diluted and washed twice with PBS to obtain PBMC from the top and neutrophils from the bottom. T-lymphocytes were isolated using T-cells enrichment columns (R\&D Systems) and their purity ( $>90 \%)$ was assessed using flow cytometry.

To isolate neutrophils, the high-density layer was subjected to hypotonic lysis $(155 \mathrm{mM} \mathrm{NH} 4 \mathrm{Cl}, 10 \mathrm{mM}$ KHCO3, 0.1 mM EDTA, pH 7.4) for 15 minutes on ice. After washing, cell purity and viability were checked by flow cytometry (Supplementary Figure 1) and microscopy. PMNs showed a purity and viability of more than $90 \%$.

\section{Evaluation of suppressive activity of neutrophils}

To evaluate the suppressive activity of neutrophils, we assessed their ability to inhibit both proliferation and activation of $\mathrm{T}$ lymphocytes.

\section{T- cell proliferation}

$5 \times 10^{5}$ of the T-lymphocytes isolated from 5 healthy donors were labelled with $1 \mu \mathrm{M}$ of Carboxyfluorescein succinimidyl ester (CFSE) (BD Pharmingen) at $37^{\circ} \mathrm{C}$ for $20 \mathrm{~min}$, then added to a 24 -well tissue culture plate in the presence of phytohaemagglutinin (PHA-P, $5 \mathrm{mg} / \mathrm{ml}$ ) (Sigma-Aldrich) and co-cultured with neutrophils (N) obtained from $8 \mathrm{HL}$ or 5 healthy subjects (matched for sex and age) at ratio 1:2 and 1:8. The T-cell proliferation measured by CFSE dilution was evaluated by flow cytometry after 72 hours. The experiments were conducted in parallel in presence of $200 \mu \mathrm{M}$ nor-NOHA.

\section{$T$-cell activation}

In addition, T-lymphocytes from 5 healthy donors were harvested, washed twice in staining buffer (PBS containing $0.2 \%$ BSA and $0.1 \%$ sodium azide) and added to a 96-well polypropylene plate at concentration $5 \times 10^{5}$ cells/well. After stimulation with $5 \mathrm{mg} / \mathrm{ml}$ PHA they were co-cultured with neutrophils $(\mathrm{N})$ obtained from $8 \mathrm{HL}$ or 5 healthy subjects at ratio 1:2 and 1:8.

Then, at 48 hours, we evaluated the expression on T-lymphocytes of some activation markers such as CD69, CD71, HLA-DR and CD3 $\zeta$. PHA-stimulated T-cells were used as control. The experiments were conducted in parallel in presence of $200 \mu \mathrm{M}$ nor-NOHA. 
Staining with respective isotype-matched control antibodies was also included for each condition to detect nonspecific background staining.

Density of expression of activation markers (Mean Fluorescent Intensity, MFI) were obtained and represented.

\section{Arginase assays}

Neutrophils were plated at $5 \times 10^{5}$ per well directly ex vivo in 96 well tissue culture plates, and washed with PBS and lysed with $0.1 \%$ Triton X-100 containing protease inhibitor (Roche, Nutley, NJ). To activate Arg-1, buffer containing Tris- $\mathrm{HCl}(25 \mathrm{mM})$ and $\mathrm{MnCl} 2(10 \mathrm{mM})$ was added and heated to $56^{\circ} \mathrm{C}$ for 10 minutes. L-arginine (0.5 M; Sigma) was added, and the samples were heated for 1 hour at $37^{\circ} \mathrm{C}$. The hydrolysis of arginine was stopped with $800 \mu \mathrm{L}$ of an acid solution mixture (H2SO4:H3PO4:H2O, 1:3:7). The amount of urea produced was determined using $9 \%$ $\alpha$-isonitrosopropriophenone and compared with a standard curve with absorbance measured at $540 \mathrm{~nm}$.

\section{Arg-1 detection by RT-PCR}

Total RNA was extracted using TRIzol reagent and quantified using UV spectrophotometer. For realtime PCR analysis of mRNA expression, $1.0 \mu \mathrm{g}$ of total RNA (in $20 \mu$ reaction volume) was reverse transcribed using reverse transcriptase (Roche Diagnostic Corp., Indianapolis, IN, USA) and oligo-dT primers in a standard reaction. The quantitative real-time polymerase chain reaction was performed by use of a LightCycler (Roche), with primers specifically designed for Arg-1 (Forward:5'CTCTAAGGGACAGCCTCGAGGA-3', Reverse: 5'-TGGGTTCACTTCCATGATATCTA-3'; Applied Biosystem) according to the gene manufacturer's recommended protocol. Each reaction was run in triplicate. Samples were quantified accordingly (LightCycler analysis software, version 3.5) using the housekeeping gene GAPDH (Forward: 5'-CCAGCCGAGCCACATCGCTC-3', Reverse: 5'-ATGAGCCCCAGCCTTCTC-3'; Roche) as standard.

\section{Western blot analysis}

Briefly, for western blot analysis $30 \mu \mathrm{g}$ of protein was loaded onto a $12 \%$ polyacrylamide gel Mini-PROTEAN $^{\circledR}$ TGX $^{\mathrm{TM}}$ (BIO-RAD) followed by electrotransfer to nitrocellulose membrane Trans-Blot ${ }^{\mathbb{R}}$ Turbo $^{\text {TM }}$ (BIO-RAD) using Trans-Blot ${ }^{\mathbb{B}}$ SD Semi-Dry Transfer Cell (BIO-RAD). After blocking, membrane was three times washed in PBS for 5 minutes and incubated with primary antibodies against Arg-1 (anti-rabbit, SigmaHPA003595). Next day, membranes were three times washed in PBS for 5 minutes and incubated with the secondary antibody FITC (anti-rabbit, Cat. No. sc-2012, Santa Cruz Biotechnology) for $1 \mathrm{~h}$ at room temperature.
The blots were visualized using Odyssey Infrared Imaging Scanner (Licor) and protein expression levels were quantified by densitometric analysis of antibody responses. Data were normalized to protein expression levels of $\beta$-actin.

\section{Immunohistochemistry and immunofluorescence}

Immunohistochemistry was performed on sections from four classical Hodgkin's lymphoma samples (2 nodular sclerosis and 2 mixed cellularity) and on sections from three lymph node samples of reactive follicular hyperplasia, using a polymer detection method as previously reported [52]. Briefly, tissue samples were fixed in $10 \%$ buffered formalin and paraffin embedded. Four-micrometers-thick sections were deparaffinized and rehydrated. The antigen unmasking technique was performed using Novocastra Epitope Retrieval Solutions pH6, pH 9 and pH 8 in PT Link Dako pre-treatment module at $98^{\circ} \mathrm{C}$ for 30 minutes.

Subsequently, the sections were brought to room temperature and washed in PBS. After neutralization of the endogenous peroxidase with $3 \% \mathrm{H}_{2} \mathrm{O}_{2}$ and $\mathrm{Fc}$ blocking by a specific protein block (Novocastra UK) the samples were incubated over night with the primary polyclonal antibody anti-human Arginase 1, 1/200 pH 9 (GeneTex Catalog Number GTX109242), at $4^{\circ} \mathrm{C}$. Staining was revealed by polymer detection kit (Novocastra) and AEC (3-amino9-ethylcarbazole) substrate-chromogen. The slides were counterstained with Harris hematoxylin (Novocastra).

For double-marker immunofluorescence analyses, two sequential rounds of single immunofluorescence staining were performed. The following primary antibodies were used: polyclonal anti-human Arginase 1, 1/200 (GeneTex); monoclonal anti-Human CD68, 1/50 (clone KP1 Dako Denmark), monoclonal anti-Human IDO, 1/100 (clone 10.1, Novus biologicals).

After Fc blocking, primary antibodies binding was revealed by fluorochrome-conjugated secondary antibodies: Alexa Fluor 488 goat anti-Rabbit $\operatorname{IgG}(\mathrm{H}+\mathrm{L}$, Invitrogen Molecular Probes, Carlsbad, CA), Alexa Fluor 568 conjugated goat anti-Mouse $\operatorname{IgG}(\mathrm{H}+\mathrm{L}$, Invitrogen Molecular Probes, Carlsbad, CA).

Negative control stainings were performed by using rabbit immune serum instead of the primary antibody. The slides were counterstained with DAPI Nucleic Acid Stain (Invitrogen Molecular Probes). All the sections were analyzed under a Zeiss Axioscope A1 optical microscope (Zeiss) equipped with fluorescence module and microphotographs were collected using a Zeiss Axiocam 503 color (Zeiss).

\section{Arginase detection in peripheral blood}

For sera collection, blood was centrifuged by 2 hours at $1600 \times \mathrm{g}$ for 10 minutes at room temperature and surnatant saved at $-80^{\circ} \mathrm{C}$ for maximum 2 months. 
Arg-1 was detected in serum of healthy volunteer donors and HL patients by a commercial ELISA kit (Biovendor CS058) following the manufacturer's instructions.

\section{Statistical methods}

Descriptive statistics were generated for analysis of results. Clinical and immunological parameters were compared by unpaired $t$-test. Baseline Arg-1 levels were correlated to Ann Arbor stage of disease, presence of B-symptoms and bulky disease, extranodal or bone marrow involvement and PET-2 status.

The cut-off of s-Arg-1 to identify patients with poor outcome was identified by the receiver operating characteristic (ROC) value with both sensitivity and specificity more than $70 \%$ in the training set to discriminate patients in complete remission versus refractory/relapsed within 24 months from the last chemo. This cut-off was applied in the validation set to compare the progression free survival (PFS) at 24 months between patients with high or not-high s-Arg-1 levels.

Progression free survival was calculated distinguishing high and not-high s-Arg-1 carrying patients according to Kaplan's Meier method.

Statistical analyses were elaborated through GraphPad Prism version 6.00 for Windows, GraphPad Software, San Diego California USA, www.graphpad. com.

\section{ACKNOWLEDGMENTS}

The authors thank all patients and nurses who contributed to the study, Dr. M. Lo Presti and Dr. S. Paratore for technical assistance in performing immunohistochemistry assays. This work was supported by Associazione Italiana contro le Leucemie (AIL) of Catania, Fondazione Catanese per lo Studio e la Cura delle Malattie Neoplastiche del Sangue (FON.CA.NE.SA) and AIRC (Associazione Italiana per la Ricerca sul Cancro).

\section{CONFLICTS OF INTEREST}

The authors declare no competing financial interests.

\section{Authors' contributions}

Conception and design: Alessandra Romano and Francesco Di Raimondo

Collection and assembly of data: Piera La Cava, Daniele Tibullo, Cesarina Giallongo, Anastasia Laura Caruso, Annalisa Chiarenza, Giovanna Motta

Protein assays and imaging: Nunziatina Laura

Parrinello, Loredana Villari, Claudio Tripodo, Stefano Pileri, Sebastiano Cosentino, Massimo Ippolito
Data analysis and interpretation: Alessandra Romano, Calogero Vetro, Nunziatina Laura Parrinello, Ugo Consoli, Andrea Gallamini, Francesco Di Raimondo Manuscript writing: All authors

Final approval of manuscript: All authors

\section{REFERENCES}

1. Montes-Moreno S. Hodgkin's Lymphomas: A Tumor Recognized by Its Microenvironment. Adv Hematol. 2011; 2011:142395.

2. Ma Y, Visser L, Roelofsen H, de Vries M, Diepstra A, van Imhoff $\mathrm{G}$, van der Wal T, Luinge M, Alvarez-Llamas $\mathrm{G}$, Vos H, Poppema S, Vonk R, van den Berg A. Proteomics analysis of Hodgkin lymphoma: identification of new players involved in the cross-talk between HRS cells and infiltrating lymphocytes. Blood. 2008; 111:2339-2346.

3. Gallamini A, Hutchings M, Rigacci L, Specht L, Merli F, Hansen M, Patti C, Loft A, Di Raimondo F, D'Amore F, Biggi A, Vitolo U, Stelitano C, et al. Early interim 2-[18F] fluoro-2-deoxy-D-glucose positron emission tomography is prognostically superior to international prognostic score in advanced-stage Hodgkin's lymphoma: a report from a joint Italian-Danish study. Journal of clinical oncology. 2007; 25:3746-3752.

4. Romano A, Vetro C, Donnarumma D, Forte S, Ippolito M, Di Raimondo F. Early interim 2-fluoro-2-deoxy-D-glucose positron emission tomography is prognostically superior to peripheral blood lymphocyte/monocyte ratio at diagnosis in classical Hodgkin's lymphoma. Haematologica. 2012; 97:e21-23; author reply e24.

5. Gallamini A, Di Raimondo F, La Nasa G, Romano A, Borra A, Greco M. Standard therapies versus novel therapies in Hodgkin lymphoma. Immunol Lett. 2013.

6. Oki Y, Chuang H, Chasen B, Jessop A, Pan T, Fanale M, Dabaja B, Fowler N, Romaguera J, Fayad L, Hagemeister F, Alma Rodriguez M, Neelapu S. The prognostic value of interim positron emission tomography scan in patients with classical Hodgkin lymphoma. British journal of haematology. 2014.

7. Biggi A, Gallamini A, Chauvie S, Hutchings $M$, Kostakoglu L, Gregianin M, Meignan M, Malkowski B, Hofman MS, Barrington SF. International validation study for interim PET in ABVD-treated, advanced-stage hodgkin lymphoma: interpretation criteria and concordance rate among reviewers. J Nucl Med. 2013; 54:683-690.

8. Gallamini A, Patti C, Viviani S, Rossi A, Fiore F, Di Raimondo F, Cantonetti M, Stelitano C, Feldman T, Gavarotti P, Sorasio R, Mulè A, Leone M, et al. Early chemotherapy intensification with BEACOPP in advancedstage Hodgkin lymphoma patients with a interim-PET positive after two ABVD courses. British journal of haematology. 2011; 152:551-560.

9. Hasenclever D, Diehl V. A prognostic score for advanced Hodgkin's disease. International Prognostic Factors Project 
on Advanced Hodgkin's Disease. The New England journal of medicine. 1998; 339:1506-1514.

10. Moccia AA, Donaldson J, Chhanabhai M, Hoskins PJ, Klasa RJ, Savage KJ, Shenkier TN, Slack GW, Skinnider B, Gascoyne RD, Connors JM, Sehn LH. International Prognostic Score in advanced-stage Hodgkin's lymphoma: altered utility in the modern era. Journal of clinical oncology. 2012; 30:3383-3388.

11. Steidl C, Lee T, Shah SP, Farinha P, Han G, Nayar T, Delaney A, Jones SJ, Iqbal J, Weisenburger DD, Bast MA, Rosenwald A, Muller-Hermelink HK, et al. Tumorassociated macrophages and survival in classic Hodgkin's lymphoma. The New England journal of medicine. 2010; 362:875-885.

12. Alizadeh D, Trad M, Hanke NT, Larmonier CB, Janikashvili N, Bonnotte B, Katsanis E, Larmonier N. Doxorubicin Eliminates Myeloid-Derived Suppressor Cells and Enhances the Efficacy of Adoptive T Cell Transfer in Breast Cancer. Cancer research. 2013.

13. Ko JS, Bukowski RM, Fincke JH. Myeloid-derived suppressor cells: a novel therapeutic target. Curr Oncol Rep. 2009; 11:87-93.

14. Ko JS, Zea AH, Rini BI, Ireland JL, Elson P, Cohen P, Golshayan A, Rayman PA, Wood L, Garcia J, Dreicer R, Bukowski R, Finke JH. Sunitinib mediates reversal of myeloid-derived suppressor cell accumulation in renal cell carcinoma patients. Clinical cancer research. 2009; 15:2148-2157.

15. Mantovani A. The growing diversity and spectrum of action of myeloid-derived suppressor cells. European journal of immunology. 2010; 40:3317-3320.

16. Ostrand-Rosenberg S. Myeloid-derived suppressor cells: more mechanisms for inhibiting antitumor immunity. Cancer immunology, immunotherapy. 2010; 59:1593-1600.

17. Romano A, Parrinello NL, Vetro C, Forte S, Chiarenza A, Figuera A, Motta G, Palumbo GA, Ippolito M, Consoli U, Raimondo FD. Circulating myeloid-derived suppressor cells correlate with clinical outcome in Hodgkin Lymphoma patients treated up-front with a risk-adapted strategy. British journal of haematology. 2014.

18. Dumitru CA, Moses K, Trellakis S, Lang S, Brandau S. Neutrophils and granulocytic myeloid-derived suppressor cells: immunophenotyping, cell biology and clinical relevance in human oncology. Cancer immunology, immunotherapy. 2012; 61:1155-1167.

19. Rodriguez PC, Ernstoff MS, Hernandez C, Atkins M, Zabaleta J, Sierra R, Ochoa AC. Arginase I-producing myeloid-derived suppressor cells in renal cell carcinoma are a subpopulation of activated granulocytes. Cancer research. 2009; 69:1553-1560.

20. Darcy CJ, Woodberry T, Davis JS, Piera KA, McNeil YR, Chen Y, Yeo TW, Weinberg JB, Anstey NM. Increased plasma arginase activity in human sepsis: association with increased circulating neutrophils. Clin Chem Lab Med. 2013:1-9.
21. Lechner MG, Megiel C, Russell SM, Bingham B, Arger N, Woo T, Epstein AL. Functional characterization of human $\mathrm{Cd} 33+$ and $\mathrm{Cd} 11 \mathrm{~b}+$ myeloid-derived suppressor cell subsets induced from peripheral blood mononuclear cells co-cultured with a diverse set of human tumor cell lines. J Transl Med. 2011; 9:90.

22. Munder M. Arginase: an emerging key player in the mammalian immune system. Br J Pharmacol. 2009; 158:638-651.

23. Raber P, Ochoa AC, Rodriguez PC. Metabolism of L-arginine by myeloid-derived suppressor cells in cancer: mechanisms of $\mathrm{T}$ cell suppression and therapeutic perspectives. Immunol Invest. 2012; 41:614-634.

24. Munder M, Mollinedo F, Calafat J, Canchado J, GilLamaignere C, Fuentes JM, Luckner C, Doschko G, Soler G, Eichmann K, Muller FM, Ho AD, Goerner M. Arginase $\mathrm{I}$ is constitutively expressed in human granulocytes and participates in fungicidal activity. Blood. 2005; 105:2549-2556.

25. Jacobsen LC, Theilgaard-Monch K, Christensen EI, Borregaard N. Arginase 1 is expressed in myelocytes/ metamyelocytes and localized in gelatinase granules of human neutrophils. Blood. 2007; 109:3084-3087.

26. Rotondo R, Bertolotto M, Barisione G, Astigiano S, Mandruzzato S, Ottonello L, Dallegri F, Bronte V, Ferrini S, Barbieri O. Exocytosis of azurophil and arginase 1-containing granules by activated polymorphonuclear neutrophils is required to inhibit $\mathrm{T}$ lymphocyte proliferation. Journal of leukocyte biology. 2011; 89:721-727.

27. Popovic PJ, Zeh HJ, 3rd, Ochoa JB. Arginine and immunity. J Nutr. 2007; 137:1681s-1686s.

28. Bronte V. Myeloid-derived suppressor cells in inflammation: uncovering cell subsets with enhanced immunosuppressive functions. European journal of immunology. 2009; 39:2670-2672.

29. Hock BD, Taylor KG, Cross NB, Kettle AJ, Hampton MB, McKenzie JL. Effect of activated human polymorphonuclear leucocytes on $\mathrm{T}$ lymphocyte proliferation and viability. Immunology. 2012; 137:249-258.

30. Munder $M$, Schneider H, Luckner C, Giese T, Langhans CD, Fuentes JM, Kropf P, Mueller I, Kolb A, Modolell M, Ho AD. Suppression of T-cell functions by human granulocyte arginase. Blood. 2006; 108:1627-1634.

31. Thewissen M, Damoiseaux J, van de Gaar J, Tervaert JW. Neutrophils and T cells: bidirectional effects and functional interferences. Molecular immunology. 2011; 48:2094-2101.

32. Choe J-Y, Yun JY, Jeon YK, Kim SH, Park G, Huh JR, Oh S, Kim JE. Indoleamine 2,3-dioxygenase (IDO) is frequently expressed in stromal cells of Hodgkin lymphoma and is associated with adverse clinical features: a retrospective cohort study. BMC Cancer. 2014; 14:1-9.

33. Porrata LF, Ristow K, Colgan JP, Habermann TM, Witzig TE, Inwards DJ, Ansell SM, Micallef IN, Johnston PB, Nowakowski GS, Thompson C, 
Markovic SN. Peripheral blood lymphocyte/monocyte ratio at diagnosis and survival in classical Hodgkin's lymphoma. Haematologica. 2012; 97:262-269.

34. Pillay J, Kamp VM, van Hoffen E, Visser T, Tak T, Lammers JW, Ulfman LH, Leenen LP, Pickkers P, Koenderman L. A subset of neutrophils in human systemic inflammation inhibits T cell responses through Mac-1. The Journal of clinical investigation. 2012; 122:327-336.

35. Rodriguez P, Zea A, Culotta K, Zabaleta J, Ochoa J, Ochoa A. Regulation of $\mathrm{T}$ cell receptor CD3zeta chain expression by L-arginine. The Journal of biological chemistry. 2002; 277:21123-21129.

36. Gunji Y, Hori S, Aoe T, Asano T, Ochiai T, Isono K, Saito T. High frequency of cancer patients with abnormal assembly of the T cell receptor-CD3 complex in peripheral blood T lymphocytes. Japanese journal of cancer research. 1994; 85:1189-1192.

37. Finke JH, Zea AH, Stanley J, Longo DL, Mizoguchi H, Tubbs RR, Wiltrout RH, O'Shea JJ, Kudoh S, Klein E, et al. Loss of T-cell receptor zeta chain and p56lck in T-cells infiltrating human renal cell carcinoma. Cancer research. 1993; 53:5613-5616.

38. Schmielau J, Finn OJ. Activated granulocytes and granulocyte-derived hydrogen peroxide are the underlying mechanism of suppression of t-cell function in advanced cancer patients. Cancer research. 2001; 61:4756-4760.

39. Darcy CJ, Minigo G, Piera KA, Davis JS, McNeil YR, Chen Y, Volkheimer AD, Weinberg JB, Anstey NM, Woodberry T. Neutrophils with myeloid derived suppressor function deplete arginine and constrain $\mathrm{T}$ cell function in septic shock patients. Critical care (London, England). 2014; 18:R163.

40. Valitutti S, Muller S, Dessing M, Lanzavecchia A. Signal extinction and $\mathrm{T}$ cell repolarization in $\mathrm{T}$ helper cellantigen-presenting cell conjugates. European journal of immunology. 1996; 26:2012-2016.

41. Sippel TR, White J, Nag K, Tsvankin V, Klaassen M, Kleinschmidt-DeMasters BK and Waziri A. Neutrophil degranulation and immunosuppression in patients with GBM: restoration of cellular immune function by targeting arginase I. Clinical cancer research. 2011; 17:6992-7002.

42. Feldmeyer N, Wabnitz G, Leicht S, Luckner-Minden C, Schiller M, Franz T, Conradi R, Kropf P, Muller I, Ho AD, Samstag Y and Munder M. Arginine deficiency leads to impaired cofilin dephosphorylation in activated human T lymphocytes. International immunology. 2012; 24:303-313.

43. Gallamini A. Positron emission tomography scanning: a new paradigm for the management of Hodgkin's lymphoma. Haematologica. 2010; 95:1046-1048.
44. Rigacci L, Puccini B, Zinzani PL, Biggi A, Castagnoli A, Merli F, Balzarotti M, Stelitano C, Spina M, Vitolo U, Stefoni V, Levis A, Gotti M, et al. The prognostic value of positron emission tomography performed after two courses (INTERIM-PET) of standard therapy on treatment outcome in early stage Hodgkin lymphoma: A multicentric study by the fondazione italiana linfomi (FIL). American journal of hematology. 2015; 90:499-503.

45. Zinzani PL, Broccoli A, Gioia DM, Castagnoli A, Ciccone G, Evangelista A, Santoro A, Ricardi U, Bonfichi M, Brusamolino E, Rossi G, Anastasia A, Zaja F, et al. Interim Positron Emission Tomography ResponseAdapted Therapy in Advanced-Stage Hodgkin Lymphoma: Final Results of the Phase II Part of the HD0801 Study. Journal of clinical oncology. 2016.

46. Marri PR, Hodge LS, Maurer MJ, Ziesmer SC, Slager SL, Habermann TM, Link BK, Cerhan JR, Novak AJ, Ansell SM. Prognostic significance of pretreatment serum cytokines in classical Hodgkin lymphoma. Clinical cancer research. 2013; 19:6812-6819.

47. Gallamini A AC, Tripodo C, et al. 9th International Symposium on Hodgkin Lymphoma Cologne, Germany, October 12-15, 2013. Haematologica. 2013; 98:1-64.

48. Bonfante V, Santoro A, Viviani S, Valagussa P, Bonadonna G. ABVD in the treatment of Hodgkin's disease. Semin Oncol. 1992; 19:38-44; discussion 44-35.

49. Santoro A, Bonadonna G. Prolonged disease-free survival in MOPP-resistant Hodgkin's disease after treatment with adriamycin, bleomycin, vinblastine and dacarbazine (ABVD). Cancer Chemother Pharmacol. 1979; 2:101-105.

50. Barrington SF, Qian W, Somer EJ, Franceschetto A, Bagni B, Brun E, Almquist H, Loft A, Højgaard L, Federico M, Gallamini A, Smith P, Johnson P. Concordance between four European centres of PET reporting criteria designed for use in multicentre trials in Hodgkin lymphoma. Eur J Nucl Med Mol Imaging. 2010; 37:1824-1833.

51. Meignan M, Gallamini A, Itti E, Barrington S, Haioun C, Polliack A. Report on the Third International Workshop on Interim Positron Emission. Leukemia \& lymphoma. 2012; 53:1876-1881.

52. Tripodo C, Sangaletti S, Guarnotta C, Piccaluga PP, Cacciatore M, Giuliano M, Franco G, Chiodoni C, Sciandra M, Miotti S, Calvaruso G, Care A, Florena AM, et al. Stromal SPARC contributes to the detrimental fibrotic changes associated with myeloproliferation whereas its deficiency favors myeloid cell expansion. Blood. 2012; 120:3541-3554. 